\title{
Escitalopram induced syndrome of inappropriate antidiuretic hormone in elderly: an interesting scenario
}

\author{
Tarun Sharma ${ }^{1}$, Aradhna Sharma ${ }^{2}$, Madhvi Kaistha $^{3}$, Rajneet Kaur ${ }^{4}$
}

${ }^{1}$ Department of Medicine, Civil Hospital Kangra, Himachal radishh, India

${ }^{2}$ Department of Pharmacology, ${ }^{4}$ Department of Physiology, Dr. RPGMC Kangra, Himachal

Pradesh, India

${ }^{3}$ Health and Family Welfare Regional Training Institute Cheb, Kangra, Himachal Pradesh, India

Received: 10 April 2016 Accepted: 07 May 2016

*Correspondence to:

Dr. Tarun sharma,

Email: tarunpgi@gmail.com

Copyright: (C) the author(s), publisher and licensee Medip Academy. This is an openaccess article distributed under the terms of the Creative Commons Attribution NonCommercial License, which permits unrestricted noncommercial use, distribution, and reproduction in any medium, provided the original work is properly cited.

\begin{abstract}
Selective serotonin reuptake inhibitors (SSRI) are the first line drugs used in the treatment of endogenous depression. Though clinically well tolerated in elderly, hyponatremia is one of the recognized side effects and its pathophysiology may be linked to syndrome of inappropriate antidiuretic hormone (SIADH). This side effect of SSRIs is a serious one since it can cause death also, if not diagnosed at the onset. This is an interesting case of an elderly patient who developed hyponatremia which further related to SIADH induced by escitalopram, an SSRI. The patient had symptomatic improvement in depression within one month but symptoms of hyponatremia appeared and then deteriorated again. Severe hyponatremia, serum hypo-osmolality, urine osmolality, and measurable levels of plasma antidiuretic hormone suggested SIADH. The hyponatremia improved after stoppage of the offending drug along with conservative medical therapy in hospital. Clinicians should be aware of this uncommon but significant side effect of escitalopram and monitor high-risk patients for the development of SIADH.
\end{abstract}

Keywords: SIADH, SSRI, Escitalopram, Hyponatremia

\section{INTRODUCTION}

Both selective serotonin reuptake inhibitors (SSRI) and serotonin norepinephrine reuptake inhibitors (SNRI) are being used as first-line therapeutic medications for depression. Escitalopram is the newly approved SSRI which is structurally related to its parent compound citalopram but with better tolerable side effect profile. Most of the side effects of escitalopram are nonserious and include headache, diarrhoea and nausea. While hyponatremia and syndrome of inappropriate secretion of antidiuretic hormone (SIADH) are recognized serious side effects of other SSRIs and SNRIs. ${ }^{1}$ A very few case reports of escitalopram induced hyponatremia and SIADH have been documented in the literature till date. As elderly patients are predisposed to hyponatremia due to medical comorbidities, concomitant drugs, and advanced age by itself, the use of a SSRI in the elderly is more likely to aggravate hyponatremia., ${ }^{2,3}$ Here, we describe an older patient who developed severe hyponatremia most likely related to SIADH caused by escitalopram, an SSRI, who was successfully treated with discontinuation of the antidepressant and water restriction with salt intake and saline. 


\section{CASE REPORT}

A 79 year old male patient was brought with altered sensorium which developed over 4 days and was progressive in nature. Historically the patient had a variety of depressive symptoms. He had a medical history of hypertension, hyperlipidemia, and diabetes with history of complete heart block for which patient was on permanent pacemaker. His daily medication prior to admission consisted of amlodipine $10 \mathrm{mg}$, rosuvastatin $20 \mathrm{mg}$, metformin $1 \mathrm{gm}$, sitagliptin $100 \mathrm{mg}$ and aspirin $75 \mathrm{mg}$ along with $20 \mathrm{mg}$ of escitalopram. Patient had symptoms of major depression one month back and he became home bound. His day to day activities also suffered. He stopped talking to family members also. $\mathrm{He}$ would sit in dark room alone and never asked for any food. Patient was started on $10 \mathrm{mg}$ of escitalopram. His symptoms improved a little but still he was home bound. The dose of escitalopram was increased to $20 \mathrm{mg}$ and clonazepam $0.5 \mathrm{mg}$ was added for sleep. There was improvement in his symptoms and he started going outdoors and started doing his day to day activities. But since last four days (ten days after increasing the dose of escitalopram) attendant's again experienced deterioration his health and since one day he became obtunded. There was incontinence of urine and stools. There was no fever and no episodes of abnormal body movements. He was barely arousable. His blood sugar levels were $123 \mathrm{mg} / \mathrm{dl}$ fasting. His blood pressure was $126 / 90$ on admission, respiratory rate of $18 / \mathrm{min}$ and temperature of $98.8^{\circ} \mathrm{F}$.

Laboratory findings on admission included low levels of serum sodium $(111 \mathrm{meq} / \mathrm{l})$ and chloride $(91 \mathrm{meq} / \mathrm{l})$ and a normal hemoglobin and total leukocyte count. A chest radiograph and computed tomograms of the brain were normal except for mild frontal lobe atrophy. He had low serum osmolality $(240 \mathrm{mosm} / \mathrm{kg})$; normal is 275 to 290 , low urine sodium (19 meq/l) and urine osmolality of 123 mosm $/ \mathrm{kg}$; normal is 50 to 1300 . Escitalopram induced SIADH was postulated and the drug was discontinued. Rests of the medicines were continued. The plasma ADH concentration was normal and the patient had normal thyroid function. After admission a ryle's tube (RT) and folley's catheter were inserted. Salt intake was increased via RT along with restricted free water. Patient was started on $3 \%$ normal saline after calculating the sodium deficit along with vitals monitoring.

Following intravenous sodium replacement therapy and improvement in the patient's hyponatremia, there was improvement in sensorium. In the next 48 hours patient started talking and accepting orally. His ryle's tube and folley's were removed. His sodium levels increased to $127 \mathrm{meq} / 1$. Therapy was continued and serum sodium normalized after 5 days of therapy. Subsequently sodium levels remained within the normal range without replacement of saline intake and discontinuation of escitalopram therapy.

\section{DISCUSSION}

SIADH has been reported to occur in between $0.5 \%$ to $32 \%$ of patients receiving SSRI. ${ }^{3}$ Symptoms of SIADH are characterized by hyponatremia and range from mild lethargy, insomnia, headache and confusion to coma. ${ }^{4}$ The mechanism of SIADH with SSRI/SNRI remains unclear. One proposed hypothesis involves SIADH induction via the release of $\mathrm{ADH}$ (serotonin effects on $5-\mathrm{HT}_{2}$ and 5$\mathrm{HT}_{1 \mathrm{c}}$ receptors) or increased renal responsiveness to ADH, which is supported by animal studies. ${ }^{5}$ SSRI/SNRI inhibit norepinephrine reuptake to a certain extent, which suggests that norepinephrine induction of ADH release via 1 -adrenergic receptors may lead to SIADH induction. ${ }^{4}$ Drug interactions between SSRI/SNRI and medications that can cause hyponatremia are another possible explanation. SSRI are known to inhibit a number of cytochrome p-450 iso-enzymes. ${ }^{4}$ This inhibition leads to elevated serum concentrations of these medications, which in turn augments their effects on sodium homeostasis.

However, the frequency of SIADH in the elderly is extremely high, and ranges from $12 \%$ to $33 \% .{ }^{6}$ Elderly are more predisposed to hyponatremia due to various physiological changes in water homeostasis. In the elderly, the maximal diluting and concentrating capacity of the kidney is impaired and ADH secretion may be slightly increased. ${ }^{7,8}$ The ADH response to osmolar stimuli has been shown to be greater in the elderly than in young control subjects. ${ }^{9}$ This increased osmo-sensitivity may increase the risk of SIADH. The risk of developing SIADH also increases with the other comorbidities like diabetes, HTN and concomitant drugs known to cause hyponatremia or alter secretion of $\mathrm{ADH} .^{10}$

The pathologic findings in our case can be summarized as follows:

- Comorbidities before the start of escitalopram.

- Emergence of hyponatremia associated with neurological symptoms after one month of escitalopram therapy-more so 10 days after increasing the dose of escitalopram.

- Serum sodium and physical symptoms returned to normal shortly after discontinuation of escitalopram.

- Replacement of saline intake to maintain serum sodium levels was not needed subsequently after stopping escitalopram.

$\mathrm{ADH}$ levels were not suppressed appropriately despite low plasma osmolality in our case, and the clinical course showed that the serum sodium level decreased excessively when an SSRI was started and normalized when use of the SSRI was discontinued. Therefore, escitalopram induced SIADH and hyponatremia were suspected in our case. On WHO-UMC causality assessment scale the causal association was found to be probable in nature. 
It is not easy to predict severe hyponatremia when initiating treatment with an SSRI/SNRI. Awareness of this pathological condition is important because serious hyponatremia may be mistaken for worsening of depression, as features of hyponatremia mimic certain depressive symptoms. Even more important is awareness that most episodes of serious drug-induced hyponatremia are reversed rapidly through discontinuation of treatment with the suspected drug, initiation of fluid restriction, and/or salt intake. ${ }^{4}$

\section{CONCLUSION}

Multiple factors may predispose the elderly to SSRI/SNRI related hyponatremia. Moreover, the symptoms of hyponatremia can easily be misinterpreted as a worsening of depressive disorder. Therefore, when patients are placed on SSRI, clinicians should give careful consideration to any medical comorbidities, conditions, or drug interactions, and monitor serum sodium concentrations during the entire course of treatment in order to be able to detect and treat hyponatremia and/or SIADH early on.

Funding: No funding sources

Conflict of interest: None declared

Ethical approval: Not required

\section{REFERENCES}

1. Movig KL, Leufkens HG, Lenderink AW, Egberts AC. Serotonergic antidepressants associated with an increased risk for hypona-tremia in the elderly. Eur J Clin Pharmacol. 2002;58:143-8.
2. Rosner MH. Severe hyponatremia associated with the combined use of thiazide diuretics and selective serotonin reuptake inhibitors. Am J Med Sci. 2004;327:109-11.

3. Jacob S, Spinler SA. Hyponatremia associated with selective serotonin-reuptake inhibitors in older adults. Ann Pharmacotherapy. 2006;40:1618-22.

4. Guay D. Hyponatremia associated with selective serotonin reuptake inhibitors: clinical review. Consult Pharmacist. 2000;15:160-77.

5. Anderson IK, Martin GR, Ramage AG. Central administration of 5-HT activates 5-HT1A receptors to cause sympatho excitation and 5-HT2/5-HT1C receptors to release vasopressin in anaesthetized rats. Br J Pharmacol. 1992;107:1020-8.

6. Rottmann CN. SSRIs and the syndrome of inappropriate antidiuretic hormone secretion: close monitoring of serum sodium levels in high-risk patients taking SSRIs can prevent this condition and the resulting hyponatremia, which can be lethal. Am J Nurs. 2007;107:51-8.

7. Lindeman RD, Van Buren HC, Raisz LG. Osmolar renal concentrating ability in healthy young men and hospitalized patients without renal disease. $\mathrm{N}$ Eng $\mathbf{J}$ Med. 1960;262:1306-9.

8. Miller M. Fluid and electrolyte balance in the elderly. Geriatrics. 1987;42:65-76.

9. Helderman JH, Vestal RE, Rowe JW, Tobin JD, Anders R, Robertson GL. The response of arginine vasopressin to intravenous ethanol and hypertonic saline in man: the impact of aging. J Gerontol. 1987;33:39-47.

10. Kirby D, Ames D. Hyponatremia and selective serotonin re-uptake inhibitors in elderly patients. Int J Geriatr Psychiatry. 2001;16:484-93.

Cite this article as: Sharma T, Sharma A, Kaistha M, Kaur R. Escitalopram induced syndrome of inappropriate antidiuretic hormone secretion in elderly: an interesting scenario. Int J Basic Clin Pharmacol 2016;5:1131-3. 